\title{
Gene Expression Changes in the Jejunum of Rats during the Transient Suckling-Weaning Period
}

\author{
Kazuki MochIZUKI, Satoko YorITA and Toshinao GoDA* \\ Laboratory of Nutritional Physiology, Graduate School of Nutritional and Environmental Sciences and Global \\ COE, The University of Shizuoka, 52-1 Yada, Shizuoka, Shizuoka 422-8526, Japan
}

(Received September 3, 2008)

\begin{abstract}
Summary It is well-known that the small intestine of rodents rapidly undergoes differentiation and maturation during the transient suckling-weaning period from postnatal days 13 to 27 . In the present study, we examined the gene expression changes in the jejunum of rats during the transient suckling-weaning period by microarray analysis. In the microarray data, we found that the expressions of many genes related to digestion/absorption/ excretion of nutrients/ions, such as members of the solute carrier (Slc) family and ATP-binding cassette $(A b c)$ subfamily, were rapidly induced during this period. Furthermore, some transcriptional factors/cofactors (Thrsp, Ppargc1a, Klf15 and Vdr), which are presumably important for the induction of intestinal gene expression after weaning, were rapidly induced during this period. In contrast, genes related to transport of nutrients, such as folate, zinc, fat and phosphate, which are important for early development, were highly expressed in the suckling period and then gradually decreased during weaning. These results indicate that the jejunum matures during the suckling-weaning period accompanied by changes in the expression of many genes related to digestion/absorption/excretion and some genes for transcriptional factors/cofactors.
\end{abstract}

Key Words transient suckling-weaning period, jejunum, solute carrier family, ATP-binding cassette subfamily, transcriptional factors/cofactors

The morphology of the small intestine in rodents changes dramatically during the first $2-3 \mathrm{wk}$ after birth as they are gradually weaned. During this period, the diet composition changes from one with less carbohydrate (milk) to one rich in carbohydrate (solid food) (1). Several studies have already shown that the expressions of genes related to carbohydrate digestion/absorption, such as disaccharidases [sucrase-isomaltase $(\mathrm{Si})$ and trehalase (Treh)], which are involved in the digestion of starch/sucrose or trehalose into monosaccharides, and hexose transporters [SGLT1 (Slc5a1), GLUT5 (Slc2a5) and GLUT2 (Slc2a2)], which are involved in monosaccharide absorption from the lumen, are elevated between 2 and $3 \mathrm{wk}$ after birth in rodents (2-5). In addition, we previously reported that the gene expressions of liver-type fatty acid-binding protein [L-FABP (Fabp1)] and cellular retinol-binding protein type II [CRBPII (Rbp2)], which are involved in transporting fatty acids and vitamin A, respectively, from the lumen to enterocytes, as well as a $\beta$-oxidation rate-controlling gene [acyl-CoA oxidase (Acox1)], were highly expressed in the transient suckling-weaning period, and declined after weaning $(6,7)$. Furthermore, the gene expression of peroxisome proliferator-activated receptor $\alpha$ [PPAR $\alpha$ (Ppara)], a transcriptional factor for these genes, was associated with these gene expression changes (6).

*To whom correspondence should be addressed.

E-mail: gouda@u-shizuoka-ken.ac.jp
These changes during the transient suckling-weaning period may be regulated by the nutritional changes as well as hormones, such as thyroid hormone and glucocorticoid hormone, because such hormones are induced in serum during this period (1). It is most likely that the expressions of many genes related to digestion/ absorption, including the genes described above, are changed during this period to allow adaptation to the dietary transition from milk to solid food as well as the development of pups into adults.

Based on these observations, several studies have searched for genes upregulated and downregulated by nutrient factors and hormones in the postnatal small intestine of rodents using microarray analyses. Agbemafle et al. (8) examined glucocorticoid hormoneresponsive genes during the suckling period by microarray analysis. Cui et al. $(9,10)$ showed that fructoseresponsive genes, such as glucose-6-phosphatase, fructose-1, 6-bisphosphatase and the PI3 kinase cascade, were upregulated by fructose perfusion in weaning rats. However, these observations only focused on glucocorticoid hormone- or fructose-responsive genes, and the detailed changes in gene expression in the rat small intestine during the transient suckling-weaning period remain unknown.

In the present study, we examined the jejunal gene expression changes between postnatal day 13 (start of the weaning period) and day 27 (end of the weaning period) by microarray analysis. Our results suggest that 
Table 1. Sequences of the oligonucleotide primers used for real-time RT-PCR.

\begin{tabular}{|c|c|}
\hline Gene name & Sequence \\
\hline \multirow[t]{2}{*}{ Solute carrier family 13, member 1} & 5'-CGTGACCTTGGTGATCTTCAT-3' \\
\hline & 5'-GAAAACAGGACTGACCAACCA-3' \\
\hline \multirow[t]{2}{*}{ Cubilin (intrinsic factor-cobalamin receptor) } & 5'-GTTCCAGCTACATGGGATTCA-3' \\
\hline & 5'-CCTCGGATAAACCACTGACAA-3' \\
\hline \multirow[t]{2}{*}{ Aquaporin 3} & 5'-GGGATTGTTTTTGGGCTCTAC-3' \\
\hline & 5'-GCCATTGACCATATCCAAGTG-3' \\
\hline \multirow{2}{*}{$\begin{array}{l}\text { Solute carrier family } 28 \text { (sodium-coupled nucleoside } \\
\text { transporter), member } 1\end{array}$} & 5'-GAGTGGCTTGGTGACAAGAAA-3' \\
\hline & 5'-GAAGTTGGCAAATCCACAGAG-3' \\
\hline \multirow{2}{*}{$\begin{array}{l}\text { Solute carrier family } 16 \text { (monocarboxylic acid transporters), } \\
\text { member } 3\end{array}$} & 5'-AGTTTGAGGTGCTCATGGCTA-3' \\
\hline & 5'-GTAAACTTTCGTTGCGTCCAG-3' \\
\hline \multirow[t]{2}{*}{ ATP-binding cassette, sub-family G (WHITE), member 8} & 5'-TTTGACCTGGTCCTTCTGATG-3' \\
\hline & 5'-GGACAAGGGTAGCCAATTGAT-3' \\
\hline \multirow[t]{2}{*}{ ATP-binding cassette, sub-family G (WHITE), member 5} & 5'-CAGGTGGTGATTATGCGTCTT-3' \\
\hline & 5'-ATGTTGTTCTGGACTCGGAGA-3' \\
\hline \multirow[t]{2}{*}{ Trehalase (brush-border membrane glycoprotein) } & 5'-GAATGACACTGAGGCCAAAAG-3' \\
\hline & 5'-TGGAGGGATAAAACTCCAGGT-3' \\
\hline \multirow[t]{2}{*}{ Thyroid hormone-responsive protein } & 5'-GAGAATGAGGCTGCTGAAACA-3' \\
\hline & 5'-TCAGGTGGGTAAGGATGTGAT-3' \\
\hline \multirow{2}{*}{$\begin{array}{l}\text { Peroxisome proliferative-activated receptor, gamma, } \\
\quad \text { coactivator } 1 \alpha\end{array}$} & 5'-ATTCAAGCCAGTGCTACCTGA-3' \\
\hline & 5'-ATTTCCTGGTCTTGGAGCTGT-3' \\
\hline \multirow[t]{2}{*}{ Kruppel-like factor 15} & 5'-CСAACTTGAACCTGTCCTCAA-3' \\
\hline & 5'-AAGTTCTGCTGCTGGGTTCTT-3' \\
\hline \multirow{2}{*}{ Vitamin D receptor } & 5'-ATCATGTTACGCTCCAACCAG-3' \\
\hline & 5'-GAACTTTATGAGGGGCTCGAT-3' \\
\hline \multirow[t]{2}{*}{ Solute carrier family 27 (fatty acid transporter), member 2} & 5'-AACTACAACATCCGTGCCAAG-3' \\
\hline & 5'-CTCCTTTTTCAGGGTTGGAAG-3' \\
\hline \multirow[t]{2}{*}{ Folate receptor 1 (adult) } & 5'-CTGCTGTGCTGTGTGAGAAAA-3' \\
\hline & 5'-ACTCATGACCTCGGCATAGAA-3' \\
\hline \multirow[t]{2}{*}{ Solute carrier family 30 (zinc transporter), member 2} & 5'-GTACAGCGGTTGATTTCTGGA-3' \\
\hline & 5'-CAGCCCCATTATGATGTTCAC-3' \\
\hline \multirow[t]{2}{*}{ Solute carrier family 34 (sodium phosphate), member 3} & 5'-GCCGGAGACATTTTTAAGGAC-3' \\
\hline & 5'-ATGCTGACCACGATAGAGGAA-3' \\
\hline \multirow{2}{*}{$\begin{array}{l}\text { Potassium voltage-gated channel, Isk-related subfamily, } \\
\text { member } 1\end{array}$} & 5'-CAACTGTTCTGCCTTTTCTGG-3' \\
\hline & 5'-ACCCAGCACCATGAGGATATAG-3' \\
\hline \multirow{2}{*}{$18 \mathrm{~S}$ rRNA } & 5'-GAACGCGTGCATTTATCAGA-3' \\
\hline & 5'-GATCGGCCCGAGGTTATCTA-3' \\
\hline
\end{tabular}

the small intestine matures during the transient suckling-weaning period with changes in the expressions of many genes related to digestion/absorption/excretion and some genes for transcriptional factors/cofactors.

\section{MATERIALS AND METHODS}

Animals. Suckling Sprague-Dawley rats (Japan SLC, Inc., Hamamatsu, Japan) were kept with their mothers, and both mothers and pups were given free access to a standard laboratory chow diet (MF; Oriental Yeast Co., Ltd., Tokyo, Japan) throughout the experimental period. The rat pups were killed by decapitation between 15:00 and 16:00 at 5, 13, 20, 27 and $42 \mathrm{~d}$ of age. The experimental procedures used in the present study met the guidelines of the Animal Usage Committee of the University of Shizuoka, Japan.

Preparation of intestinal samples. The entire small intestine was removed and the jejunoileum was divided into two segments of equal length. The proximal half of the jejunoileum was flushed twice with ice-cold $0.9 \%$ $\mathrm{NaCl}$ solution. A 1-cm segment $(100 \mathrm{mg})$ was excised from the middle region of the jejunal loop (regarded as the jejunum in the present study) and immediately used for RNA extraction.

Microarray analysis. Total RNA was extracted using a previously described acidified guanidine thiocyanate method (11). Aliquots (100 ng) of total RNA pooled from 6 animals at postnatal day 13 or 27 were individually converted to cRNA and labeled with biotin using a two-cycle labeling kit (Affymetrix, Tokyo, Japan) according to the manufacturer's instructions. Aliquots $(10 \mu \mathrm{g})$ of biotin-labeled cRNA from rats at postnatal days 13 and 27 were separately hybridized to Rat 2.0 Microarrays (Affymetrix) according to the manufacturer's protocol. After washing steps, the microarray plates were analyzed with a GeneChip Scanner 3000 (Affymetrix). Data analysis was performed using the GeneChip Operating System (GCOS; Affymetrix) and Excel (Microsoft). Variable spots detected by the algorithm in GCOS in both plates were defined as nonexpressed genes and removed. Normalization of biotinlabeled signals was carried out by the global median 
normalization. Data were represented by base 2 logarithms. Biological reproducibility was confirmed in 4-8 rats by real-time RT-PCR, as indicated in "Results."

Quantitative reverse transcription-polymerase chain reaction (RT-PCR). Total RNA samples $(1.5 \mu \mathrm{g})$ were converted into cDNA by RT using Super Script ${ }^{\mathrm{TM}}$ III reverse transcriptase (Invitrogen, Tokyo, Japan) according to the manufacturer's instructions. To quantitatively estimate the mRNA levels of each gene, PCR amplification was performed using a Light-Cycler system (Roche Molecular Biochemicals, Tokyo, Japan). Real-time PCR amplifications were carried out in a total volume of $20 \mu \mathrm{L}$ containing $400 \mathrm{~nm}$ each of gene-specific primers, cDNA and SYBR Premix Ex Taq (Takara, Shiga, Japan). The amplification conditions were as follows: denaturation at $94^{\circ} \mathrm{C}$ for $15 \mathrm{~s}$, and annealing and extension at $60^{\circ} \mathrm{C}$ for $25 \mathrm{~s}$. The cycle threshold (CT)-values of each gene and $18 \mathrm{~S}$ rRNA detected by real-time RT-PCR were converted to signal intensities by the delta-delta method (12), which calculates the difference in one CT-value as a two-fold difference between the signal for each gene and the signal for a normalization gene (18S rRNA). The formula used was: $2^{\text {(CT each gene-CT } 18 \mathrm{~S} \text { rRNA) }}$. The sequences of the PCR primer pairs and the fragment sizes are shown in Table 1.

Statistical analysis. Results were expressed as means \pm SE. The significance of differences between groups was determined by Dunn's multiple range test based on the nonparametric Kruskal-Wallis test. Values of $p<0.05$ were considered to indicate statistical significance.

\section{RESULTS}

To examine whether jejunal gene expression is altered during the transient suckling-weaning period, we performed microarray analyses using total RNA extracted from the jejunum of rats at postnatal day 13 (start of the weaning period) and day 27 (end of the weaning period). Genes with signal ratios higher than 3 or lower than -3 by $\log _{2}$ between days 13 and 27 were regarded as significant changes and subjected to further analysis. Among the 21,167 gene signals detected, 131 genes were significantly upregulated $(0.62 \%)$ and 185 genes were significantly downregulated $(0.87 \%)$ in the jejunum of rats at postnatal day 27 compared with day 13. The upregulated and downregulated genes in the jejunum of rats at day 27 were classified into 7 groups based on their functions, i.e., cell cycle, digestion/ absorption/excretion, energy/metabolism, signal transduction, structural protein, transcription and others/ unknown (Tables 2-4). Many genes related to digestion/absorption/excretion (10.7\%) and energy/metabolism $(22.1 \%)$ were upregulated at day 27 , whereas genes related to energy/metabolism $(7.6 \%)$ were downregulated.

Among the upregulated and downregulated genes, we focused on the groups of genes related to digestion/ absorption/excretion and transcription. The upregulated genes included many transporters for sulfate [e.g., solute carrier family 13, member 1 (Slc13a1)], nucleo-
Table 2. Functional classification of genes changed in the microarray analyses.

\begin{tabular}{lcc}
\hline Functional category & $\begin{array}{c}\text { Number of } \\
\text { upregulated genes }\end{array}$ & $\begin{array}{c}\text { Number of } \\
\text { downregulated genes }\end{array}$ \\
\hline Cell cycle-related & $1(0.76 \%)$ & $2(1.1 \%)$ \\
Digestion/absorption/ & $14(10.7 \%)$ & $6(3.2 \%)$ \\
$\quad$ excretion & & $14(7.6 \%)$ \\
Energy/metabolism & $29(22.1 \%)$ & $8(4.3 \%)$ \\
Signal transduction & $6(4.6 \%)$ & $4(2.2 \%)$ \\
Transcription & $4(3.1 \%)$ & $3(1.6 \%)$ \\
Structural protein & $2(1.5 \%)$ & $148(80 \%)$ \\
Others/unknown & $76(58.0 \%)$ & 185 \\
$\quad$ & 131 & \\
\multicolumn{1}{c}{ Total } & &
\end{tabular}

sides [e.g., solute carrier family 28, member 1 (Slc28a1)], monocarboxylic acid [e.g., solute carrier family 16, member 3 (Slc16a3)], and lipids and sterols [e.g., ATP-binding cassette, sub-family G, member 8 (Abcg8), ATP-binding cassette, sub-family G, member 5 $(A b c g 5)]$, and genes concerned with carbohydrate digestion such as sucrase-isomaltase (Si) and trehalase (Treh). Several transcriptional factors, such as thyroid hormone-responsive protein (Thrsp), peroxisome proliferative-activated receptor, gamma coactivator $1 \alpha$ (Ppargc1a), Kruppel-like factor 15 (Klf15) and vitamin D receptor $(V d r)$, which are presumably important for intestinal maturation and expression of genes related to digestion/absorption/excretion were also detected. Among the downregulated genes, we found transporters for fatty acids [e.g., solute carrier family 27, member 2 (Slc27a2)], zinc [e.g., solute carrier family 30, member 2 (Slc30a2)], phosphate [e.g., solute carrier family 34, member 2 (Slc34a3)] and folate [e.g., folate receptor 1 (Folr1)].

We performed real-time RT-PCR for selected genes in 4-8 animals of each group to confirm the microarray data. We tested 8 upregulated genes for digestion/ absorption [Slc13a1, Treh, cubilin (Cubn, a receptor for intrinsic factor-vitamin B12), aquaporin (Aqp3), Slc28a1, Slc16a3, Abcg8 and Abcg5] (Fig. 1) and 4 upregulated genes for transcriptional factors/cofactors [Thrsp, Ppargc1a, Klf15 and Vdr] (Fig. 2). We confirmed that the mRNA levels of all these genes except Slc16a3 were significantly elevated at postnatal day 27 compared with days 5 and $13(p<0.05)$. The mRNA level of Slc16a3 was significantly higher at day 42 than at days 5 and 13 . We also confirmed by real-time RT-PCR that the gene expressions of alkaline phosphatase 3, intestine (akp3) categorized under the energy/metabolism group and secretory carrier membrane protein 5 (Scamp5) categorized under the structural protein group were upregulated (data not shown).

Next, we tested 5 downregulated genes related to digestion/absorption/excretion [solute carrier family 34, member 3 (Slc34a3), potassium voltage-gated channel, member 1 (Kcne1), solute carrier family 27 member 2 (Slc27a2), folate receptor 1 (Folr1) and solute carrier family 30, member 2 (Slc30a2)] by quantitative RT-PCR (Fig. 3). The mRNA levels of all these genes 
Table 3. Upregulated genes in small intestine during the transient suckling-weaning period.

\begin{tabular}{|c|c|c|c|c|}
\hline & Unigene ID & Symbol & Description & $\log _{2}$ ratio \\
\hline Cell cycle & Rn.125257 & Rcbtb2 & $\begin{array}{l}\text { Regulator of chromosome condensation and BTB } \\
\text { domain-containing protein } 2\end{array}$ & 3.12 \\
\hline \multirow{13}{*}{$\begin{array}{l}\text { Digestion } \\
\text { /absorption } \\
\text { /excretion }\end{array}$} & Rn.9699 & Slc13a1 & Solute carrier family 13 , member 1 & 8.68 \\
\hline & Rn.163015 & Treh & Trehalase & 6.94 \\
\hline & Rn.3236 & Cubn & Cubilin & 5.64 \\
\hline & Rn.11109 & Aqp3 & Aquaporin 3 & 5.04 \\
\hline & Rn.10517 & Slc28a1 & Solute carrier family 28 , member 1 & 4.95 \\
\hline & Rn.7329 & Slc41a2_predicted & Solute carrier family 41, member 2 (predicted) & 3.86 \\
\hline & Rn.10821 & Slc13a2 & Solute carrier family 13, member 2 & 3.70 \\
\hline & Rn.10057 & $\mathrm{Si}$ & Sucrase-isomaltase & 3.70 \\
\hline & Rn.10826 & Slc16a3 & Solute carrier family 16 , member 3 & 3.22 \\
\hline & Rn.56142 & Хрпрер2 & X-prolyl aminopeptidase 2 , membrane-bound & 3.11 \\
\hline & Rn.161892 & Abcg 8 & ATP-binding cassette, sub-family G, member 8 & 3.09 \\
\hline & Rn.91079 & Phlpb & Phospholipase B & 3.03 \\
\hline & Rn.74258 & $A b c g 5$ & ATP-binding cassette, sub-family G, member 5 & 3.00 \\
\hline \multirow{30}{*}{$\begin{array}{l}\text { Energy } \\
\text { /metabolism }\end{array}$} & Rn.31786 & Rdh7 & Retinol dehydrogenase 7 & 10.27 \\
\hline & Rn.24945 & Ugt $2 b 3$ & UDP glycosyltransferase 2 family, member 3 & 9.40 \\
\hline & Rn.5722 & Cyp4f1 & Cytochrome P450, family 4, subfamily F, polypeptide 2 & 9.13 \\
\hline & Rn.54025 & Abo & ABO blood group & 8.86 \\
\hline & Rn.138122 & $a k p 3$ & Alkaline phosphatase 3 , intestine & 7.09 \\
\hline & Rn.33492 & Cyp4a3 & Cytochrome P450, subfamily 4A, polypeptide 11 & 6.40 \\
\hline & Rn. 51389 & $\mathrm{Ca} 4$ & Carbonic anhydrase 4 & 5.96 \\
\hline & Rn.42073 & Tmem $45 b$ & Transmembrane protein $45 \mathrm{~b}$ & 5.87 \\
\hline & Rn.10352 & Cyp1a1 & Cytochrome P450, family 1 , subfamily a, polypeptide 1 & 5.86 \\
\hline & Rn.1647 & $\mathrm{Ca3}$ & Carbonic anhydrase 3 & 5.56 \\
\hline & Rn.19324 & Gba3_predicted & Glucosidase, beta, acid 3 (predicted) & 5.55 \\
\hline & Rn.14280 & $\mathrm{Cmah}$ & Cytidine monophospho-N-acetylneuraminic acid hydroxylase & 5.40 \\
\hline & Rn.86651 & $C y p 4 b 1$ & Cytochrome P450, family 4 , subfamily b, polypeptide 1 & 5.08 \\
\hline & Rn.91353 & Cyp $2 b 2$ & Cytochrome P450, family 2, subfamily b, polypeptide 15 & 4.93 \\
\hline & Rn.92401 & Cyp4a1 & Cytochrome P450, family 4 , subfamily a, polypeptide 10 & 4.87 \\
\hline & Rn.23676 & $A k r 1 b 8$ & Aldo-keto reductase family 1 , member $\mathrm{B} 8$ & 4.61 \\
\hline & Rn.6887 & Cda_predicted & Cytidine deaminase (predicted) & 4.37 \\
\hline & Rn.74044 & Aldh1a7 & Aldehyde dehydrogenase family 1 , subfamily A4 & 4.17 \\
\hline & Rn.1023 & Scd1 & Stearoyl-coenzyme A desaturase 1 & 4.07 \\
\hline & Rn.14280 & Cmah & Cytidine monophospho- $N$-acetylneuraminic acid hydroxylase & 3.93 \\
\hline & Rn.101932 & Upp1 & Uridine phosphorylase 1 & 3.81 \\
\hline & Rn.13145 & Hnmt & Histamine $N$-methyltransferase & 3.76 \\
\hline & Rn.22857 & Chdh & Choline dehydrogenase & 3.71 \\
\hline & Rn.10678 & Fut2 & Fucosyltransferase 2 & 3.54 \\
\hline & Rn.55542 & Duox 2 & Dual oxidase 2 & 3.49 \\
\hline & Rn.12593 & Gmps & Guanine monophosphate synthetase & 3.47 \\
\hline & Rn.10383 & Oas1 & $2^{\prime}, 5^{\prime}$-oligoadenylate synthetase $1,40 / 46 \mathrm{kDa}$ & 3.34 \\
\hline & Rn.6051 & Dpep1 & Dipeptidase 1 & 3.29 \\
\hline & Rn.164424 & Papss2_predicted & 3'-Phosphoadenosine 5'-phosphosulfate synthase 2 & 3.20 \\
\hline & Rn.98159 & Adh4 & Alcohol dehydrogenase 4 , pi polypeptide & 3.02 \\
\hline \multirow{6}{*}{$\begin{array}{l}\text { Signal } \\
\text { transduction }\end{array}$} & Rn.144587 & Hgfac & Hepatocyte growth factor activator & 6.14 \\
\hline & Rn.15848 & Sdcbp 2 & Syndecan-binding protein 2 & 4.81 \\
\hline & Rn.23566 & Gprc5a & G protein-coupled receptor, family $\mathrm{C}$, group 5 , member A & 4.67 \\
\hline & Rn.10198 & Gucy $2 g$ & Guanylate cyclase $2 \mathrm{~g}$ & 4.63 \\
\hline & Rn.9762 & Oprl1 & Opioid receptor-like 1 & 4.26 \\
\hline & Rn.160023 & RGD1309362 & Similar to interferon-inducible GTPase & 3.60 \\
\hline \multirow[t]{4}{*}{ Transcription } & Rn.81140 & Thrsp & Thyroid hormone responsive protein & 3.74 \\
\hline & Rn.19172 & Ppargc1a & Peroxisome proliferative-activated receptor, gamma, coactivator 1 alpha & 3.56 \\
\hline & Rn.22556 & Klf15 & Kruppel-like factor 15 & 3.42 \\
\hline & Rn.10911 & $V d r$ & Vitamin D receptor & 3.05 \\
\hline \multirow{2}{*}{$\begin{array}{l}\text { Structural } \\
\text { protein }\end{array}$} & Rn.24420 & Scamp 5 & Secretory carrier membrane protein 5 & 3.87 \\
\hline & Rn.23056 & Tmem86a & Transmembrane protein $86 \mathrm{~A}$ (predicted) & 3.64 \\
\hline
\end{tabular}


Table 4. Downregulated genes in small intestine during the transient suckling-weaning period.

\begin{tabular}{|c|c|c|c|c|}
\hline & Unigene ID & Symbol & Description & $\log _{2}$ ratio \\
\hline \multirow[t]{2}{*}{ Cell cycle } & Rn.107838 & Atrx & $\begin{array}{l}\text { Alpha thalassemia/mental retardation syndrome X-linked } \\
\text { homolog }\end{array}$ & -4.02 \\
\hline & Rn.163223 & Kifap3_predicted & Kinesin-associated protein 3 & -3.58 \\
\hline \multirow{6}{*}{$\begin{array}{l}\text { Digestion } \\
\text { /absorption } \\
\text { /excretion }\end{array}$} & Rn.15318 & Slc34a3 & Solute carrier family 34 , member 3 & -6.07 \\
\hline & Rn.9734 & Kcne1 & $\begin{array}{l}\text { Potassium voltage-gated channel, Isk-related subfamily, } \\
\text { member } 1\end{array}$ & -5.44 \\
\hline & Rn.3608 & Slc27a2 & Solute carrier family 27, member 2 & -3.63 \\
\hline & Rn.6912 & Folr1 & Folate receptor 1 & -3.55 \\
\hline & Rn.87769 & Cacna1a & $\begin{array}{l}\text { Calcium channel, voltage-dependent, } \mathrm{P} / \mathrm{Q} \text { type, alpha } 1 \mathrm{~A} \\
\text { subunit }\end{array}$ & -3.25 \\
\hline & Rn.11135 & Slc30a2 & Solute carrier family 30, member 2 & -3.21 \\
\hline \multirow{14}{*}{$\begin{array}{l}\text { Energy } \\
\text { /metabolism }\end{array}$} & Rn.10494 & Mthfr_predicted & 5,10-Methylenetetrahydrofolate reductase (predicted) & -5.05 \\
\hline & Rn.24631 & $\mathrm{Hgd}$ & Homogentisate 1,2-dioxygenase & -4.94 \\
\hline & Rn.5078 & Ass & Argininosuccinate synthetase & -4.79 \\
\hline & Rn.11326 & Cte1 & Cytosolic acyl-CoA thioesterase 1 & -4.74 \\
\hline & Rn.128560 & Neu1 & Neuraminidase 1 & -4.42 \\
\hline & Rn.114492 & LOC 304860 & Similar to $\mathrm{N}$-acetylneuraminate pyruvate lyase & -4.36 \\
\hline & Rn.14744 & Nox 4 & NADPH oxidase 4 & -4.04 \\
\hline & Rn.29180 & Apobec 3 & Apolipoprotein B editing complex 3 & -3.94 \\
\hline & Rn.29594 & Hmgcs 2 & 3-Hydroxy-3-methylglutaryl-coenzyme A synthase 2 & -3.92 \\
\hline & Rn.4220 & Echdc1 & Enoyl coenzyme A hydratase domain-containing 1 & -3.60 \\
\hline & Rn.7291 & Pcyt2 & Phosphate cytidylyltransferase 2 , ethanolamine & -3.58 \\
\hline & Rn.3651 & Bdh2_predicted & 3-Hydroxybutyrate dehydrogenase, type 2 (predicted) & -3.47 \\
\hline & Rn.39302 & Efhc2_predicted & EF-hand domain-containing 2 (predicted) & -3.45 \\
\hline & Rn.64591 & Asl & Argininosuccinate lyase & -3.36 \\
\hline \multirow{8}{*}{$\begin{array}{l}\text { Signal } \\
\text { transduction }\end{array}$} & Rn.64169 & Paqr9_predicted & Progestin and adipoQ receptor family member IX (predicted) & -5.79 \\
\hline & Rn.19093 & $\begin{array}{l}\text { RGD1562829 } \\
\text { predicted }\end{array}$ & $\begin{array}{l}\text { Similar to RAS-like, estrogen-regulated, growth-inhibitor } \\
\text { (predicted) }\end{array}$ & -5.12 \\
\hline & Rn.122003 & Akap 5 & A kinase anchor protein 5 & -5.08 \\
\hline & Rn.11225 & Gcgr & Glucagon receptor & -4.40 \\
\hline & Rn.6589 & Anxa3 & Annexin A3 & -3.52 \\
\hline & Rn.11237 & Dio3 & Deiodinase, iodothyronine, type III & -3.34 \\
\hline & Rn.77572 & $\operatorname{Igf} 2 b p 1$ & Insulin-like growth factor 2 , binding protein 1 & -3.23 \\
\hline & Rn.144573 & Homer3 & Homer homolog 3 & -3.17 \\
\hline \multirow[t]{4}{*}{ Transcription } & Rn.9659 & Tfec & Transcription factor EC & -8.79 \\
\hline & Rn.24948 & Ncor 1 & Nuclear receptor co-repressor 1 & -5.90 \\
\hline & Rn.11258 & Shox 2 & Short stature homeobox 2 & -3.43 \\
\hline & Rn.37030 & Ctdspl_predicted & CTD small phosphatase-like (predicted) & -3.25 \\
\hline \multirow{3}{*}{$\begin{array}{l}\text { Structural } \\
\text { protein }\end{array}$} & Rn.11783 & Cldn14 & Claudin 14 & -6.02 \\
\hline & Rn.52066 & Vill & Villin-like (predicted) & -4.36 \\
\hline & Rn.83592 & Cdh10 & Cadherin 10 & -3.83 \\
\hline
\end{tabular}

were significantly decreased in the jejunum of rats at postnatal day 27 compared with day $13(p<0.05)$. We also confirmed by real-time RT-PCR that the gene expressions of claudin 14 (Cldn14), villin-like (Vill) and cadherin 10 (Cdh10) categorized under the structural protein group were downregulated (data not shown).

\section{DISCUSSION}

In the present study, we performed microarray analyses to identify jejunal genes that exhibited changes in expression during the transient suckling-weaning period. Interestingly, many genes related to digestion/ absorption/excretion (10.7\%) and energy/metabolism (22.1\%) were upregulated at postnatal day 27 compared with day 13. In addition, the expressions of many genes related to energy/metabolism (7.6\%) were downregulated. During this period, the diet composition changes from one with less carbohydrate (milk) to one rich in carbohydrate (solid food). It seems as though the expression changes of many genes related to digestion/ absorption/excretion and energy/metabolism allow for adaptation to the nutritional changes occurring during this period.

In this study, we focused on genes related to diges- 


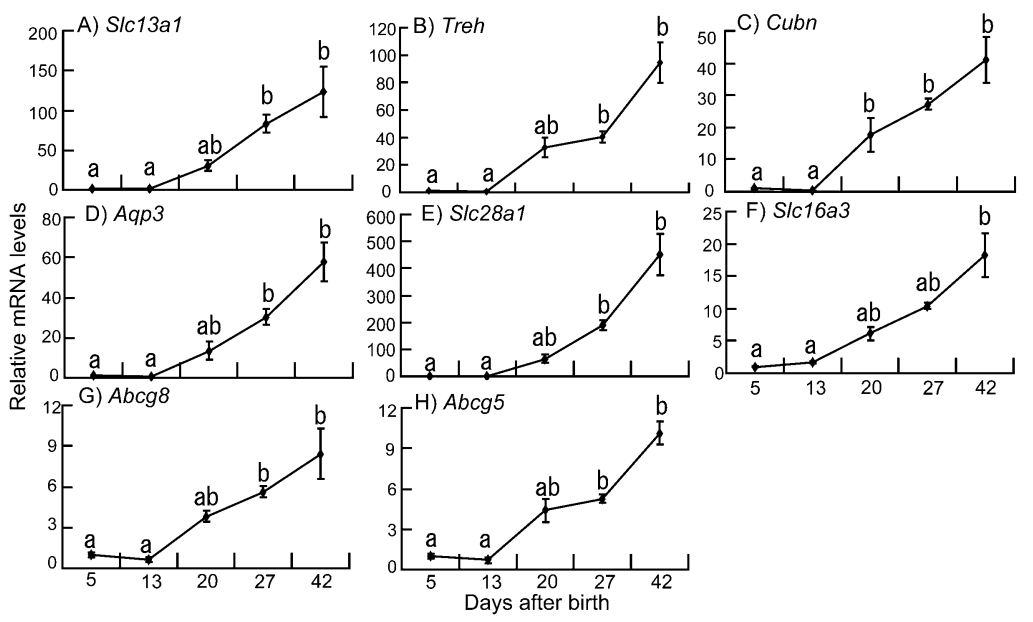

Fig. 1. Quantitative RT-PCR analysis of genes categorized under a subgroup related to digestion/absorption/excretion selected as upregulated genes from the microarray data. The mRNA levels were normalized by the $18 \mathrm{~S}$ rRNA abundance. Means \pm SE of 4-8 animals are shown. a-c: Values not sharing a common superscript differ significantly $(p<0.05)$ from one another by Dunn's multiple range test.

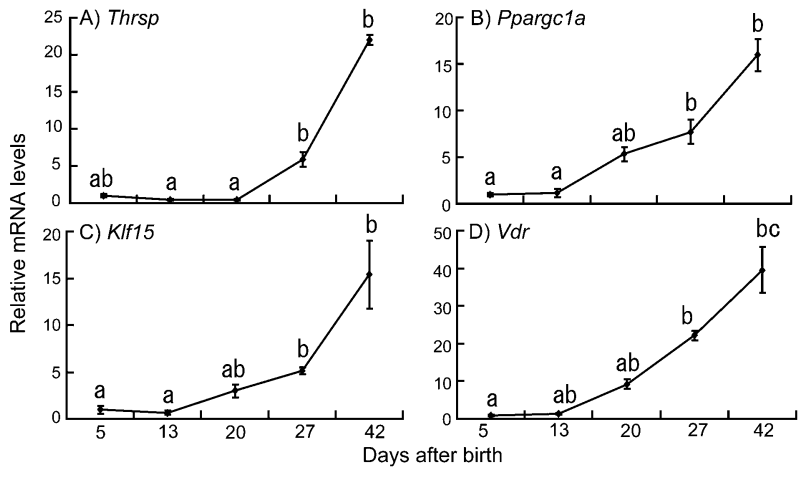

Fig. 2. Quantitative RT-PCR analysis of genes categorized under a subgroup related to transcription selected as upregulated genes from the microarray data. The mRNA levels were normalized by the $18 \mathrm{~S}$ rRNA abundance. Means \pm SE of 4-8 animals are shown. a-c: Values not sharing a common superscript differ significantly $(p<0.05)$ from one another by Dunn's multiple range test.

tion/absorption/excretion because changes in the expressions of these genes are important for functions of the intestine. We found that the gene expressions of $\mathrm{Si}$ and Treh, belonging to the disaccharidase family, increased rapidly from postnatal days 13 to 27 . These results are consistent with previous reports $(2,3,5)$. In addition, several studies have shown that the expressions of hexose transporter genes are induced during this transient period $(4,13)$. Furthermore, we found that the expression of akp3, one of the subtypes of intestinal alkaline phosphatase, increased rapidly during the transient suckling-weaning period. It has already been reported that the gene expression of another type of intestinal alkaline phosphatase, alpi, an intestinal differentiation marker, increases rapidly in the rat jejunum during the transient suckling-weaning period (14). Taken together, these results indicate that the expressions of genes related to disaccharidases and hexose transporters increase during the transient suckling-

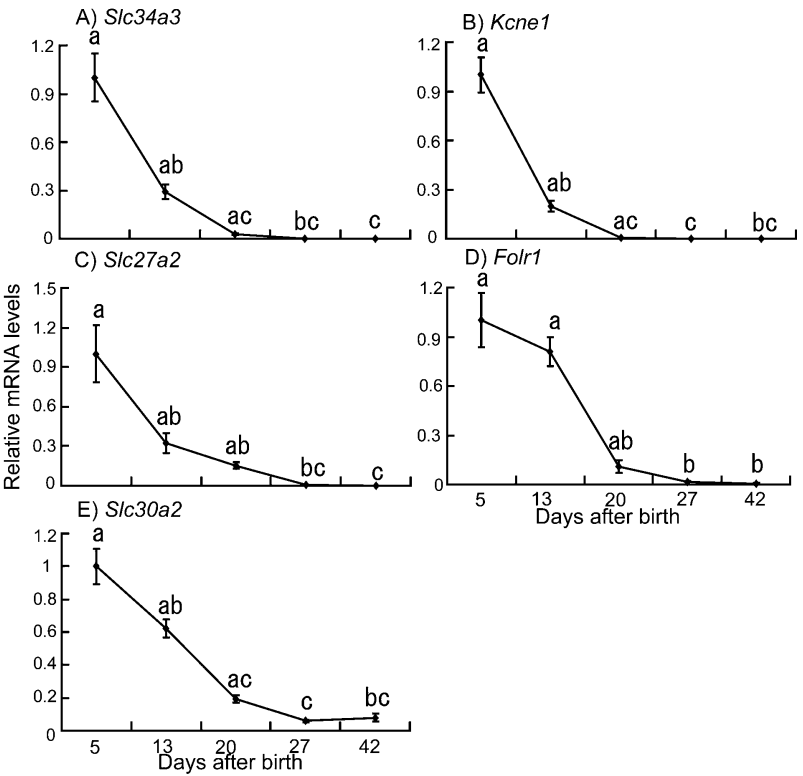

Fig. 3. Quantitative RT-PCR analysis of genes categorized under a subgroup related to digestion/absorption/ excretion selected as downregulated genes from the microarray data. The mRNA levels were normalized by the $18 \mathrm{~S}$ rRNA abundance. Means \pm SE of 4-8 animals are shown. a-c: Values not sharing a common superscript differ significantly $(p<0.05)$ from one another by Dunn's multiple range test.

weaning period accompanied by increased expressions of intestinal differentiation markers. Interestingly, our microarray analyses revealed that the expressions of many genes belonging to the solute carrier family, which are related to absorption of nutrients/ions, were higher at the end of the weaning period (postnatal day 27) than at the start of the weaning period (day 13). Real-time RT-PCR analyses showed that Slc13a1, a transporter for sulfate, which has important roles in growth and development as a substrate for bone and cartilage $(15,16)$, increased rapidly. Slc28a1, a transporter for nucleosides such as adenosine and uridine 
(17), and Slc16a3, a monocarboxylic acid transporter that transports lactic acid and pyruvate (18), were also upregulated at postnatal day 27. Abcg5 and Abcg8, members of the superfamily of ATP-binding cassette $(A b c)$ transporters, were elevated during the transient weaning-suckling period. The heterodimer of ABCG5 and ABCG8 promotes the efflux of cholesterol and plant sterols from enterocytes back into the intestinal lumen for excretion (19). The reason why the expressions of $A b c g 5$ and $A b c g 8$ are induced during the transient suckling-weaning period may involve the excretion of cholesterol and plant sterols largely flowing from solid food in the small intestine after weaning. $\mathrm{Cubn}$, a receptor for intrinsic factor-vitamin $\mathrm{B}_{12}$ complexes (20), and aqp3, a water channel protein that facilitates the transport of nonionic small solutes such as urea and glycerol (21), were also elevated. It should be noted that vitamin $\mathrm{B}_{12}$ is largely absorbed from the ileum (20). Therefore, it is necessary to investigate cubn gene expression in the ileum during the postnatal period. Taking all these results together, the expressions of many genes related to digestion/absorption/excretion of nutrients/ions, which are presumably important for growth after weaning, were increased during the transient sucklingweaning period.

To seek evidence for the factors that regulate the induction of these gene expressions during the transient suckling-weaning period in the small intestine, we focused on upregulated genes related to transcription. We found that the expressions of 4 such genes [Thrsp, Ppargc 1a, Klf15 and Vdr] were upregulated during the transient suckling-weaning period. Thrsp, which is normally referred to as Spot 14, was originally identified in liver and adipose tissues. It is thought that Thrsp may regulate the expressions of genes related to fatty acid synthesis in liver and adipose tissues because the expression of Thrsp in these tissues is closely associated with fatty acid synthesis and carbohydrate inflow (22). Several recent studies have revealed that THRSP acts as a coactivator by interacting with nuclear transcriptional factors such as thyroid hormone receptor (23, $24)$, chicken ovalbumin upstream promoter-transcription factor 1 (COUP-TF1) (25) and the p53 coactivator ZAC1 (24). Another study supports the notion that THRSP acts an activator of transcription because it promoted cell growth in breast cancer cell lines (26). In addition, we found that expression of Ppargc1a was increased during the transient suckling-weaning period. PPARGC1A regulates genes involved in energy metabolism as a transcriptional coactivator that interacts with many nuclear transcriptional factors, including PPAR $\gamma$, nuclear respiratory factors (NRFs), cAMP response element-binding protein (CREB), hepatocyte nuclear factor 4 (HNF-4) and glucocorticoid receptor (GR) $(27,28)$. It is known that Slc2a5, one of the upregulated genes during the transient suckling-weaning period, is induced by cAMP and CREB is activated by cAMP (29). In addition, HNF-4 enhances the expression of intestinal genes, such as apolipoprotein A-IV (30) and guanylyl cyclase (31), although these genes are not listed among the upregulated/downregulated genes. It is reported not only that glucocorticoid hormone enhanced intestinal genes such as Si, Slc $2 a 5$ and Treh (5, 13, 32), but also that GR directly regulated Slc2a5 expression $(13,33)$. PPARGC1A may enhance intestinal gene expressions by activating transcriptional factors such as CREB, HNF-4 and GR. KLF15, listed among the upregulated genes is a transcriptional factor that regulates differentiation and genes related to insulin sensitivity, such as glucose transporter (GLUT) 4, in adipocytes $(34,35)$ and gluconeogenesis by inducing phosphoenolpyruvate carboxykinase (PEPCK) gene expression in the liver $(36,37)$. Because these factors are categorized under the coactivator group (THRSP and PPARGC1A) and a transcriptional factor (KLF15) related to energy metabolism, and many genes related to digestion/absorption/excretion and transcription are presumably required for adapting to nutritional changes during the transient suckling-weaning period, the inductions of these gene expressions during this period may enhance the intestinal expression of genes categorized as upregulated genes in this study. In addition, we found that vitamin D receptor $(V d r)$ was induced during this period. Previous studies have shown that VDR regulates calcium absorption by regulating related genes such as calcium transporter 1 and calbindin- $\mathrm{D}_{9 \mathrm{~K}}$ in the small intestine $(38-40)$. Our present results support the notion proposed in a previous study using $V d r$ null mice (41) that vitamin D is important for development after weaning. Although these genes such as calcium transporter 1 and calbindin- $\mathrm{D}_{9 \mathrm{~K}}$ were not listed among the upregulated genes, it was reported that these gene expressions were induced during the transient suckling-weaning period in the mouse small intestine (42). Furthermore, we detected upregulation of Slc13a1, a transporter for sulfate that plays important roles in growth and development as a substrate for bone and cartilage $(15,16)$, although it is unknown whether its expression is regulated by VDR. Further studies are required to investigate whether the induction of these gene expressions is regulated by VDR. It should be noted that the expressions of Ppargc1a, Klf15 and Vdr gradually increased from day 13 to day 42 . The period in which the increases began corresponds to the timing when serum thyroid hormones and glucocorticoid hormones increase rapidly. The inductions of Ppargc1a, Klf15 and $V d r$ may be affected by these hormones. Regarding Thrsp, upregulation by Thrsp during postnatal development is limited to the period between day 20 and day 42 . Thus, THRSP is not concerned with initial induction of genes in up-regulated genes listed from day 13 to day 20. Considering that this period corresponds to the timing when the amount of carbohydrate inflow into the small intestine increases dramatically and that the expression of Thrsp is associated with inflow of carbohydrates in the liver (43), expression of Thrsp in the small intestine may be induced by carbohydrate flow and involved in enhancing gene expressions by dietary carbohydrates after day 20. It is necessary to further investigate whether these 
transcriptional coactivators/factors regulate jejunal induction of gene expressions during the transient suckling-weaning period.

Finally, we focused on downregulated genes categorized under the digestion/absorption group in the jejunum during the transient suckling-weaning period. We found that an isozyme belonging to the long-chain fatty-acid-coenzyme A ligase family, Slc27a2 (44), was among the downregulated genes. Slc27a2 plays a key role in $\beta$-oxidation (44). Higher expression of Slc27a2 during the suckling period in the jejunum may be important for energy generation from fat because milk contains large amounts of fat and our previous studies showed that the gene expressions of rate-controlling enzymes of $\beta$-oxidation, such as acyl-CoA oxidase, are highly expressed during the suckling-weaning period $(6,7)$. We also detected the zinc transporter Slc30a2 (45) among the downregulated genes. Zinc is an important nutrient for mammals, particularly during the suckling period (46). Our data support this notion because Slc30a2 was highly expressed during the suckling period. The sodium phosphate transporter Slc $34 a 3$ (47) and folate receptor 1 (Folr1) (48) found among the downregulated genes at postnatal day 27 are reportedly important for development/cell growth, although their intestinal functions during the suckling-weaning period are unclear. These results indicate that several nutrient transporters, which are reported to be important for early development, may be important for nutrient transport in suckling rats. Although it remains unknown which transcriptional factors regulate gene expressions listed among the downregulated genes during the suckling period, we detected transcriptional factors such as Tfec, Ncor1, Shox 2 and Ctdspl among the downregulated genes. It is necessary in further studies to examine whether these transcriptional factors regulate the genes downregulated during the sucklingweaning period. Our recent studies indicated that the expressions of genes related to dietary fat absorption and $\beta$-oxidation in the rat small intestine during suckling are enhanced by dietary fat in milk through activation of the nuclear receptor $\operatorname{PPAR} \alpha$, which directly binds fatty acids as ligands $(6,7)$. Another recent study revealed that $S l c 27 a 2$ in the mouse small intestine is induced by $\operatorname{PPAR} \alpha(49)$. Thus, $\operatorname{PPAR} \alpha$ is one of the transcriptional factors that enhance gene expression in the rat small intestine during the suckling period.

Overall, we have demonstrated that the expressions of many genes, particularly those related to digestion/ absorption/excretion and transcription, are upregulated during the transient suckling-weaning period. These expression changes during the transient suckling-weaning period are associated with small intestinal morphological changes as well as the change in diet from milk to solid food. Therefore, the changes may be due to stimulation for intestinal differentiation/maturation as well as stimulation by nutrients. Indeed, it was reported that endogenous stimulation by thyroid hormones and glucocorticoid hormones in suckling rats induces intestinal maturation (50). Furthermore, it is known that glucocorticoid hormones (Si, Slc2a5 and Treh) and thyroid hormones (Si, Slc2a5 and Treh) enhance intestinal gene expressions during the transient suckling-weaning period $(4,5,13,32)$. In addition, the expressions of these genes are known to be upregulated by dietary carbohydrate $(9,10,51,52)$. Therefore, the changes in gene expression between days 13 and 27 detected in our microarray analysis may be regulated by these hormones and dietary factors.

In conclusion, the results of the present study suggest that the expressions of genes related to digestion/ absorption and transcription in the small intestine are changed during the transient suckling-weaning period. The issues of which nutritional/hormonal factors regulate these changes in gene expression during this period remain to be clarified.

\section{Acknowledgments}

This work was supported by Grants-in-Aid for Scientific Research from the Ministry of Education, Culture, Sports, Science and Technology of Japan (18590220, 18790171), and grants from the Uehara Memorial Foundation, Global COE Program, the Center of Excellence for Innovation in Human Health Sciences, from the Ministry of Education, Culture, Sports, Science and Technology of Japan.

\section{REFERENCES}

1) Koldovsky O. 1985. Response of the gastrointestinal tract to premature weaning in experimental animals. Pediatrics 75: 199-206.

2) Fukushima A, Goda T, Motohashi Y, Sakuma K. 2004. The specific expression patterns of lactase, sucrase and calbindin- $\mathrm{D}_{9 \mathrm{~K}}$ in weaning rats are regulated at the transcriptional level. J Nutr Sci Vitaminol 50: 265-271.

3) Krasinski SD, Estrada G, Yeh KY, Yeh M, Traber PG, Rings EH, Buller HA, Verhave M, Montgomery RK, Grand RJ. 1994. Transcriptional regulation of intestinal hydrolase biosynthesis during postnatal development in rats. Am J Physiol 267: G584-594.

4) Mochizuki K, Yagi E, Sakaguchi N, Mochizuki H, Takabe S, Kuranuki S, Suzuki T, Shimada M, Goda T. 2007. The critical period for thyroid hormone responsiveness through thyroid hormone receptor isoform $\alpha$ in the postnatal small intestine. Biochim Biophys Acta 1770: 609-616.

5) Gartner H, Shukla P, Markesich DC, Solomon NS, Oesterreicher TJ, Henning SJ. 2002. Developmental expression of trehalase: Role of transcriptional activation. Biochim Biophys Acta 1574: 329-336.

6) Mochizuki K, Mochizuki H, Kawai H, Ogura Y, Shimada M, Takase S, Goda T. 2007. Possible role of fatty acids in milk as the regulator of the expression of cytosolic binding proteins for fatty acids and vitamin A through PPAR $\alpha$ in developing rats. J Nutr Sci Vitaminol 53: 515521.

7) Mochizuki K, Suruga K, Yagi E, Takase S, Goda T. 2001. The expression of PPAR-associated genes is modulated through postnatal development of PPAR subtypes in the small intestine. Biochim Biophys Acta 1531: 68-76.

8) Agbemafle BM, Oesterreicher TJ, Shaw CA, Henning SJ. 2005. Immediate early genes of glucocorticoid action on the developing intestine. Am J Physiol Gastrointest 
Liver Physiol 288: G897-906.

9) Cui XL, Schlesier AM, Fisher EL, Cerqueira C, Ferraris RP. 2005. Fructose-induced increases in neonatal rat intestinal fructose transport involve the PI3-kinase/Akt signaling pathway. Am J Physiol Gastrointest Liver Physiol 288: G1310-1320.

10) Cui XL, Soteropoulos P, Tolias P, Ferraris RP. 2004. Fructose-responsive genes in the small intestine of neonatal rats. Physiol Genomics 18: 206-217.

11) Chomczynski P, Sacchi N. 1987. Single-step method of RNA isolation by acid guanidinium thiocyanate-phenol-chloroform extraction. Anal Biochem 162: 156159.

12) Livak KJ, Schmittgen TD. 2001. Analysis of relative gene expression data using real-time quantitative PCR and the 2(-delta delta C(t)) method. Methods 25: 402-408.

13) Douard V, Cui XL, Soteropoulos P, Ferraris RP. 2008. Dexamethasone sensitizes the neonatal intestine to fructose induction of intestinal fructose transporter (SLC2A5) function. Endocrinology 149: 409-423.

14) Hodin RA, Meng S, Chamberlain SM. 1994. Thyroid hormone responsiveness is developmentally regulated in the rat small intestine: A possible role for the $\alpha$-2 receptor variant. Endocrinology 135: 564-568.

15) Markovich D, Murer H. 2004. The slc13 gene family of sodium sulphate/carboxylate cotransporters. Pflugers Arch 447: 594-602.

16) Lee H, Hubbert ML, Osborne TF, Woodford K, Zerangue N, Edwards PA. 2007. Regulation of the sodium/sulfate co-transporter by farnesoid X receptor $\alpha$. J Biol Chem 282: 21653-21661.

17) Gray JH, Owen RP, Giacomini KM. 2004. The concentrative nucleoside transporter family, SLC28. Pflugers Arch 447: 728-734.

18) Halestrap AP, Meredith D. 2004. The slc16 gene family from monocarboxylate transporters (MCTs) to aromatic amino acid transporters and beyond. Pflugers Arch 447: 619-628.

19) Lammert F, Wang DQ. 2005. New insights into the genetic regulation of intestinal cholesterol absorption. Gastroenterology 129: 718-734.

20) Kozyraki R. 2001. Cubilin, a multifunctional epithelial receptor: An overview. J Mol Med 79: 161-167.

21) Ma T, Verkman AS. 1999. Aquaporin water channels in gastrointestinal physiology. J Physiol 517 (Pt 2): 317326.

22) LaFave LT, Augustin LB, Mariash CN. 2006. S14: Insights from knockout mice. Endocrinology 147: 4044-4047.

23) Chou WY, Cheng YS, Ho CL, Liu ST, Liu PY, Kuo CC, Chang HP, Chen YH, Chang GG, Huang SM. 2007. Human spot 14 protein interacts physically and functionally with the thyroid receptor. Biochem Biophys Res Commun 357: 133-138.

24) Chou WY, Ho CL, Tseng ML, Liu ST, Yen LC, Huang SM. 2008. Human spot 14 protein is a p53-dependent transcriptional coactivator via the recruitment of thyroid receptor and ZAC1. Int J Biochem Cell Biol 40: 18261834.

25) Compe E, de Sousa G, Francois K, Roche R, Rahmani R, Torresani J, Raymondjean M, Planells R. 2001. Spot 14 protein interacts and co-operates with chicken ovalbumin upstream promoter-transcription factor 1 in the transcription of the L-type pyruvate kinase gene through a specificity protein 1 (SP1) binding site. Biochem J 358:
175-183.

26) Martel PM, Bingham CM, McGraw CJ, Baker CL, Morganelli PM, Meng ML, Armstrong JM, Moncur JT, Kinlaw WB. 2006. S14 protein in breast cancer cells: Direct evidence of regulation by SREBP-1c, superinduction with progestin, and effects on cell growth. Exp Cell Res 312: $278-288$.

27) Herzig S, Long F, Jhala US, Hedrick S, Quinn R, Bauer A, Rudolph D, Schutz G, Yoon C, Puigserver P, Spiegelman B, Montminy M. 2001. CREB regulates hepatic gluconeogenesis through the coactivator PGC-1. Nature 413: 179-183.

28) Puigserver P, Spiegelman BM. 2003. Peroxisome proliferator-activated receptor- $\gamma$ coactivator $1 \alpha$ (PGC- $1 \alpha)$ : Transcriptional coactivator and metabolic regulator. Endocr Rev 24: 78-90.

29) Mahraoui L, Takeda J, Mesonero J, Chantret I, Dussaulx E, Bell GI, Brot-Laroche E. 1994. Regulation of expression of the human fructose transporter (GLUT5) by cyclic AMP. Biochem J 301 (Pt 1): 169-175.

30) Carriere V, Vidal R, Lazou K, Lacasa M, Delers F, Ribeiro A, Rousset M, Chambaz J, Lacorte JM. 2005. HNF-4dependent induction of apolipoprotein A-IV gene transcription by an apical supply of lipid micelles in intestinal cells. J Biol Chem 280: 5406-5413.

31) Swenson ES, Mann EA, Jump ML, Giannella RA. 1999. Hepatocyte nuclear factor-4 regulates intestinal expression of the guanylin/heat-stable toxin receptor. Am J Physiol 276: G728-736.

32) Leeper LL, McDonald MC, Heath JP, Henning SJ. 1998. Sucrase-isomaltase ontogeny: Synergism between glucocorticoids and thyroxine reflects increased mRNA and no change in cell migration. Biochem Biophys Res Commun 246: 765-770.

33) Takabe S, Mochizuki K, Goda T. 2008. De-phosphorylation of GR at Ser203 in nuclei associates with GR nuclear translocation and GLUT5 gene expression in Caco-2 cells. Arch Biochem Biophys 475: 1-6.

34) Gray S, Feinberg MW, Hull S, Kuo CT, Watanabe M, SenBanerjee S, DePina A, Haspel R, Jain MK. 2002. The Kruppel-like factor KLF15 regulates the insulin-sensitive glucose transporter GLUT4. J Biol Chem 277: 34322-34328.

35) Mori T, Sakaue H, Iguchi H, Gomi H, Okada Y, Takashima Y, Nakamura K, Nakamura T, Yamauchi T, Kubota N, Kadowaki T, Matsuki Y, Ogawa W, Hiramatsu R, Kasuga M. 2005. Role of Kruppel-like factor 15 (KLF15) in transcriptional regulation of adipogenesis. J Biol Chem 280: 12867-12875.

36) Gray S, Wang B, Orihuela Y, Hong EG, Fisch S, Haldar S, Cline GW, Kim JK, Peroni OD, Kahn BB, Jain MK. 2007. Regulation of gluconeogenesis by Kruppel-like factor 15. Cell Metab 5: 305-312.

37) Teshigawara K, Ogawa W, Mori T, Matsuki Y, Watanabe E, Hiramatsu R, Inoue H, Miyake K, Sakaue H, Kasuga M. 2005. Role of Kruppel-like factor 15 in pepck gene expression in the liver. Biochem Biophys Res Commun 327: 920-926.

38) Van Cromphaut SJ, Dewerchin M, Hoenderop JG, Stockmans I, Van Herck E, Kato S, Bindels RJ, Collen D, Carmeliet P, Bouillon R, Carmeliet G. 2001. Duodenal calcium absorption in vitamin D receptor-knockout mice: Functional and molecular aspects. Proc Natl Acad Sci USA 98: 13324-13329.

39) Bolt MJ, Cao LP, Kong J, Sitrin MD, Li YC. 2005. Vitamin 
D receptor is required for dietary calcium-induced repression of calbindin- $\mathrm{D}_{9 \mathrm{~K}}$ expression in mice. $J$ Nutr Biochem 16: 286-290.

40) Zheng W, Xie Y, Li G, Kong J, Feng JQ, Li YC. 2004. Critical role of calbindin- $\mathrm{D}_{28 \mathrm{~K}}$ in calcium homeostasis revealed by mice lacking both vitamin $\mathrm{D}$ receptor and calbindin- ${ }_{28 \mathrm{~K}}$ J Biol Chem 279: 52406-52413.

41) Yoshizawa T, Handa Y, Uematsu Y, Takeda S, Sekine K, Yoshihara Y, Kawakami T, Arioka K, Sato H, Uchiyama Y, Masushige S, Fukamizu A, Matsumoto T, Kato S. 1997. Mice lacking the vitamin D receptor exhibit impaired bone formation, uterine hypoplasia and growth retardation after weaning. Nat Genet 16: 391396.

42) Song Y, Peng X, Porta A, Takanaga H, Peng JB, Hediger MA, Fleet JC, Christakos S. 2003. Calcium transporter 1 and epithelial calcium channel messenger ribonucleic acid are differentially regulated by 1,25 dihydroxyvitamin D3 in the intestine and kidney of mice. Endocrinology 144: 3885-3894.

43) Towle HC, Kaytor EN, Shih HM. 1997. Regulation of the expression of lipogenic enzyme genes by carbohydrate. Annu Rev Nutr 17: 405-433.

44) Gimeno RE. 2007. Fatty acid transport proteins. Curr Opin Lipidol 18: 271-276.

45) McMahon RJ, Cousins RJ. 1998. Mammalian zinc transporters. J Nutr 128: 667-670.

46) Mutch PB, Hurley LS. 1974. Effect of zinc deficiency during lactation on postnatal growth and development of rats. J Nutr 104: 828-842.

47) Murer H, Forster I, Biber J. 2004. The sodium phosphate cotransporter family SLC34. Pflugers Arch 447: 763767.

48) Piedrahita JA, Oetama B, Bennett GD, van Waes J, Kamen BA, Richardson J, Lacey SW, Anderson RG, Finnell RH. 1999. Mice lacking the folic acid-binding protein FOLBP1 are defective in early embryonic development. Nat Genet 23: 228-232.

49) Hirai T, Fukui Y, Motojima K. 2007. PPAR $\alpha$ agonists positively and negatively regulate the expression of several nutrient/drug transporters in mouse small intestine. Biol Pharm Bull 30: 2185-2190.

50) Henning SJ, Rubin DC, Shulman RJ. 1994. Ontogeny of the intestinal mucosa. In: Physiology of the Gastrointestinal Tract (Johnson LR, ed), 3rd ed, p 571-611. Elsevier Academic Press, London.

51) Honma K, Mochizuki K, Goda T. 2007. Carbohydrate/ fat ratio in the diet alters histone acetylation on the sucrase-isomaltase gene and its expression in mouse small intestine. Biochem Biophys Res Commun 357: 1124-1129.

52) Kishi K, Tanaka T, Igawa M, Takase S, Goda T. 1999. Sucrase-isomaltase and hexose transporter gene expressions are coordinately enhanced by dietary fructose in rat jejunum. J Nutr 129: 953-956. 